\title{
Sex Work Undresses Patriarchy with Every Trick!
}

\section{Meena Saraswathi Seshu and Aarthi Pai}

\begin{abstract}
Some feminists argue that sex work reduces the female body to an object of sexual pleasure to be exploited in the marketplace by any male - an argument consistent with patriarchal notions of protection, reverence and control, the construction of women as a devi [goddess], the dasi [slave] or the veshya [sex worker]. This article addresses our work with collectivising rural women not in sex work (Vidrohi Mahila Manch [Platform for Rebellious Women] (VMM) Sangli) and rural women in sex work (Veshya Anyay Mukti Parishad (VAMP)) from South Maharashtra and North Karnataka, India. It examines the apparent control adult women in sex work have over their own bodies and lives. Although it is true that unless acting collectively, they are less successful in confronting organised criminal gangs and the brutal side of law enforcers, most of them boldly confront sexual relations with individual male clients and men from their own community.
\end{abstract}

\section{Introduction}

Is sex work violence against women? Is sex work not the epitome of patriarchy (Jenkins 2009)? These questions have been posed many times by colleagues and feminist friends and remain a contentious space, which has pitted sex worker rights activists against mainstream feminists thought and theory. Some feminists argue that sex work reduces the female body to an object of sexual pleasure to be exploited in the marketplace by any male - an argument consistent with patriarchal notions of protection, reverence and control, the construction of women as a devi [goddess], the dasi [slave] or the veshya [sex worker]. Sex work in India has always been known as dhanda, meaning business. Women in Sex Work refers to the exchange of money for the sexual service provided as 'business' at a price that is agreed upon and transacted beforehand. The service is well defined and is very specific.

There are several strands of thought within feminism on the systems of sex work and the position of the women who work in it. Debates around sex work have been centred on the dichotomy of 'prostitution' either as a human rights violation - a modern form of slavery - or as the exercise of the right to work. This debate is problematic because of the binary understanding of prostitution as either an act of slavery or as work. It pits two human rights against each other: freedom from slavery and victimhood on the one hand versus choice and the right to work on the other. The discourse fails to recognise the dynamics of an institution that encompasses a wide spectrum of elements from violence and exploitation at one end to autonomy and agency to choose the best possible options, at the other. The grey area is not in this external, obvious, and moral discussion. The politics of the female body, female sexual conditioning, and sexual control need to be broadened, and the complexities teased out and dealt with.

\section{Veshya Anyay Mukti Parishad ${ }^{1}$ (VAMP), a} collective of women in sex work with its secretariat in Sangli, challenges the feminist argument of 'exploitation by any male'. VAMP defines sex work as 'adult, monogamous or polygamous sexual partnerships within a commercial context'. The contexualisation of sex work is therefore critical: between consenting adults and where the exchange of money is part of a contract between two or more individuals. The image of the unwilling victim, forced and exploited to offer her services is an image that is informed by a false construction of sex work as sexual slavery (Farley 2004a; Barry 1979). The contract itself signifies the 'mutual' nature of the 
exchange, more so because the terms of the contract are controlled by the person/woman offering the service (Murthy and Seshu, forthcoming). VAMP agrees that sex work is work (hum kaam pe jathe hai [we go to work]).

\section{The dialogue: rural women not in sex work in conversation with rural women in sex work}

This article rests on our work with collectivising rural women not in sex work (Vidrohi Mahila Manch [Platform for Rebellious Women] (VMM) Sangli) and rural women in sex work (Veshya Anyay Mukti Parishad (VAMP)) from South Maharashtra and North Karnataka, India. It examines the apparent control adult women in sex work seem to have over their own bodies and lives. Although it is true that unless organised and in collectives, they are less successful in confronting organised criminal gangs and the brutal side of law enforcers, most of them boldly confront and challenge the prevalent malecentred sexual relations with individual men from the mainstream (clients) and men from their own community (fathers, sons, brothers, uncles, etc.).

Rural women from VMM state that as part of the class-based, caste-based and male-centred family systems, they are forced to occupy a secondary status with very little decision-making powers within and outside the family. In order to understand whether these two groups of women believed that there is indeed a separate world that is inhabited by these two groups, we decided to bring them in for a discussion and dialogue. A three-hour facilitated discussion was organised between six women from VAMP and six representatives of the rural women's group. ${ }^{2}$ The semi-structured discussion was facilitated by Meena Saraswathi Seshu and centred on the women's varying experience of 'purush pradhanatva' [patriarchy]. This conversation took place in June 2010. Sangram has been collectivising women to gain a voice and fight for rights (Nandita Kapadia Kundu 2011).

These two groups of women seemingly occupy two distinct worlds; one, the world of those who would like to control sexuality, couching it in moral terms or even in terms of societal norms or the good of the species, and the other, the world of the resistors who break the dominant norm and try to live by rules unacceptable to the dogood moralists or savers of mainstream 'norms'.

\subsection{Summary of the dialogue}

VAMP: The regular man in our lives is the malak. He is like a live-in husband who we 'keep'. We believe in multiple malaks - as the saying goes ' $e k$ undher, ek bahar, ek bimar ek tayaar'! [One who is hidden, one open, one when ill and one always on call!] If a woman in sex work opts to stay with one man and conduct her dhanda [business], she does not change her name. She continues to occupy her own residence and in fact, it is the man who comes to stay with her. In this case, the tables are reversed: it is the man who is 'kept' by the woman. Very often, if she seeks a separation from him, it is done on her terms though it can turn violent. In the work place, she is more than equal to the male client and very often controls the conditions of the transaction.

VMM: From the moment of her birth, a girl is considered 'paraya dhan' [someone else's wealth]. An outsider in the very house she is born into, she is even given a new first name on her marriage, forcing her to discard her old identity and adopt a new one. She then becomes the property of the in-laws, she loses control over herself - to be cherished or discarded depending on material [wealth] and other factors. In Sunita More's words, 'My husband changed my first name, beat me constantly and I was fed up and [had] nowhere to go till I joined Sangram, and become politicised. If it's not money, it's my family, if it's not suspicion about me it's my inability to get pregnant, if it's not my attitude towards my inlaws it's my disrespectful nazar [view] of other family members... But the beating was always justified as if the problem was with me.'

VAMP: Brothel owners/traffickers would have some control depending on the circumstances within which the woman is practising her trade, but the male clients have almost no control once they have entered the brothel. Women 'keep' many malaks and refuse to be treated as the exclusive property of one person. The business of sex work is structured to reduce the sexual act to a specific service. For instance, if a man pays Rs 50 for the sexual act, he is not allowed to exceed that limit or overstay beyond a certain time controlled by the woman. The terms of the contract are specific and cannot be violated. The structure within which sex work is practised ensures that the terms are adhered to, emphasising the control women and brothel owners have over their clients. 
VMM: In our society, we do not experience control of our body. The norms laid down by society are strictly followed, though they are almost never based on an equal footing [samsaman]. For instance, a married mother is accorded a high status but if a [woman] delivers a child out of wedlock, she is branded 'loose' and wanton. Sexual abuse by a husband is not [considered] rape, rather it is couched as a conjugal right and an expression of love; sex is a duty every married woman is expected to perform. On the other hand, if a woman chooses an undesirable male as a sexual partner [i.e. in terms of caste/religion] parents [will] invariably book the lover under rape laws. We have to uphold the 'honour' of our family, community and village.

VAMP: We experience control over our bodies differently. Working without consideration/ payment, whatever the amount may be is almost unheard of. Even with the men we 'keep' as malaks, free services are frowned upon. There are numerous stories and narratives. Har Raat suhag raat, sakkali utun smashan ghat! [Every night is like the first marriage night, next morning it's the funeral pyre!] is a common narrative that speaks to the transient male in the partnership (emotional and financial) - that speaks to the detrimental effect of male influence on emotional and financial independence. While love plays a big role it does not necessarily include duty; the relations between men and women in sex work are not clothed in hypocritical terms or disguised as ideal and honourable. Relations between the men and women in sex work, though male oriented, are conducted from the female point of view which does not accept the 'sacredness' and 'sanctity' of monogamous relationships.

VMM: In our society, we women are often treated like reproductive machines that carry, nurture and develop the suitable 'seed' for reproduction. Children are important for lineage and for inheritance. Women are closely watched and monitored lest the seeds of unwanted persons are planted in their wombs. The monitoring of reproduction by the family has always defined and governed our experience of motherhood. We think that this monitoring of women carries a hidden agenda: to protect and perpetuate caste, class and community. We have many case studies of inter-caste and inter-religion marriages that were forcibly broken by families in the name of upholding caste. In the case of the woman being pregnant, families will force abortion to avoid the mixing of caste/religion.

VAMP: With us, the 'seed' is unimportant. Any one of our clients or malaks could have impregnated us. Most women enjoy being mothers and accept the responsibility of all the siblings equally, sharing strong bonds with all their children. The cycle of reproductive power begins and ends with the mother. The most interesting phenomenon is the role of the current lover or malak. He assumes the role of father and in many instances even lends his name if needed, in school. The women themselves prefer to retain their maiden names and often have their mother's name as their middle name. The fact that the biological father is not known has no impact on the community. The child is not considered 'illegitimate' and has all the legal rights over his/her mother's property. As in Bimmawa Gollar's case, she had three children with three different malaks, two boys and a girl and they have three different surnames. But her property was distributed to all three equally. Though she gave them their father's name they have no legal proof of lineage, nor does she/they want to claim it.

VMM: You people paint a picture that is very different from our experience of men. Even when we earn money we are not considered important in the family or community. Some of us have managed to assert ourselves in our families and in the village but we have to fight for this space. Then we are not looked upon as 'normal'.

VAMP: Your society also thinks we are abnormal. Men who come to us are of many kinds. We think many of them are different but not abnormal.

For instance, the man who pays just to be able to oil and comb long hair, or the one who pays to massage us, or the one who just wants us to ride on his motorbike the whole night long, or the one who pays to just talk to us about his office issues or problems with his wife. There is no sexual service in these transactions.

\section{Discussions: many questions, some answers!}

Women in sex work became collectivised early on in the programme (1995) but the collectivisation process of rural women took longer - it started in 1997 and crystallised in 2009. Thus began the journey to unravel some of the conversations and 
experiences as articulated by these women and to explore the tremendous challenge women in sex work posed to the family structure, system and its values. We also realised that not only do women in sex work reject the moral double standards forced on them by mainstream society (Sangram 1995) but they actually challenge 'values' that govern sexual experience and sexual work.

\subsection{Reproduction and lineage}

VMM explores the experience of power (Stam 1994) in social relations within the joint family system whereas VAMP explores the experience of power within a female-headed family system. VMM also expressed that within the joint family system female members have well-defined roles in the hierarchy and that power within the family is determined and shifts by their ability to produce the male heir.

It is interesting to understand the parallel that exists within the communities of women in sex work. The emphasis is always on being a mother rather than the furtherance of a family name. The divide of sexuality for pleasure and sexuality for reproduction is not clearly demarcated either! Since reproduction is not a major goal, women in sex work are treated less as a property or a means to an end. Thus, they share more fruitful and open relationships with the men in their own communities and are also able to attain better control over their bodies which is not evident among rural women from VMM.

VMM also expressed clearly that the glorification of the expectant 'wife' as compared to the censure of an 'unwed' mother emphasises the preoccupation of the family with the womb and its aversion to a foreign 'seed' amply emphasised in the need for sanctity through marriage for reproduction. Motherhood is thus encouraged and celebrated only in controlled conditions.

\subsection{Sexual and financial control}

'We believe that we are more empowered than most women within male-dominated patriarchal structures are. For instances [sic], within the family structure (which we know is the most oppressive), we are the breadwinners and the heads of our households. The relationships we share with the men from our families are more honest and equal because the purdah of double standards is not necessary. Economic independence from men is a reality that we enjoy with pride and dignity', says the statement for VAMP (Sangram 1995).

Women from VAMP challenge the understanding of the commodification inherent in their work. They do not accept that they have sold their rights over their bodies and may have lost their identities as independent human beings. The control over their lives and bodies is a stark contrast to the total lack of control experienced by women from VMM within the family structure.

Women in sex work argue that in the transaction with their male clients, they retain a measure of control insofar as the price they set for the service offered, and the type of service offered. They also draw attention to the experience of motherhood and reproduction as it is articulated by members of VMM as clearly representing the ultimate commoditisation of the female body albeit for love, family honour and marriage.

\subsection{Providing sexual services}

VAMP argues that casual sex could be a physical act stripped of emotion, can be initiated by women, can be used in a commercial context and even be pleasurable. They state that there is nothing sacred about sex and it can be offered as a service for monetary gain. As the VAMP statement says, 'We believe that a woman's sexuality is an integral part of her as a woman, as varied as her 'mothering', 'domestic' and such other skills. We do not believe that sex has a sacred space and women who have sex for reasons other than its spiritual importance are violating this space' (Sangram 1995).

In the communities where VAMP works, anecdotal narratives show that many adult women appear out of 'nowhere' apparently comfortable with this notion of sex within a commercial context with multiple men. This challenges the idea that no woman could come into sex work on her own and that all women were forced and trafficked into sex work (Farley 2004b). Many women walk in and out of the communities challenging the notion that all women in sex work are trapped by force, deception, debt bondage and in slavery-like practice.

Within the brothel context and especially where brothels are demarcated by caste and geography the atmosphere is of a close-knit community. Allied services of serving alcohol or creating an 
ambience are all services paid for and specifically defined by components of this community rather than the woman who actually offers the sexual service. Women who walk the streets and provide services are also governed by the same rule of specific service for a specific price. Their historical proximity to the entertainment industry has also influenced this way of thinking among the women. This also plays out when women become pregnant. Women will not accept the customer as the father of their children. The service to the customer is over and the relationship with him is also over once the terms of the service provided have been completed.

\subsection{Female sexual conditioning}

The moral value of 'chaste womanhood' is centred on monogamous heterosexual relationships within marriage for the sole purpose of reproduction. Such reproduction is held sacred in order to preserve the purity of descent and ensuring continuity through male lineage. Female sexual conditioning is 'pure and sacred womanhood' wherein the acceptance of female passion is also vehemently denied expression. Such passion acquires the status of 'impure desires'. This thinking also frowns upon the explicit use of sexual parts of the female body and the overt use of the sexual self, deeming it cheap and immoral. Any deviations from this theme push the limits of acceptable female sexuality. Many women who refuse to accept the norm are deemed bad and debased and are called 'slut, tart, whore', and such like, words to depict the 'fallen' woman. The good woman is thus born. Once deemed 'bad', women who occupy the spectrum from 'loose via immoral to whore' pay a heavy price and are often stigmatised, violated and ostracised.

The 'good' women-'bad' women divide is morphed into societal consciousness, the former never willingly offering their sexual services for money and the latter who are willing to offer such services, and who are constructed as debased or worse, perpetuating the myth that neither comprehend what the other group is doing. Sex workers who do not recognise their own victim status are considered to be suffering from false consciousness. Women therefore cannot, should not and must not use their sexual organs to make money or as a site of work. Women have to be pure - in their ideals, their understanding and use of self, and the use of their bodies.
The resistance to accept sex work as work comes from this deep-seated conditioning that finds it difficult to accept that the sexual self is used in a purposeless (any use other than reproduction/ love) manner. Sex work is work, states VAMP, and dhanda is work to earn a living and includes passion, pleasure, boredom, and stress like any other work.

\subsection{Exploring feminist inclusion}

While victimhood and exploitation are easy to empathise with and mobilise around, money for sex has engendered not just noisy public debate, but quiet squeamishness even among feminists who should argue that rendering sexual services for money must be regarded as a legitimate livelihood option. Even feminists who advocate liberation from restrictive sexual mores have generally not addressed commercial sexual transactions.

Any dialogue has been difficult due to the awkwardness, hesitation and hostility from feminists towards sex workers and those working for their rights. This antagonism is puzzling, given that the natural ally for the sex workers' rights movement should have been the feminist movement, since it is precisely this arena of intense thought and action that has revolutionised perspectives on sexuality and labour, the fields that intersect with sex work.

At the core of feminist discomfort regarding sex work might be the notion that sex with multiple partners, especially casual sex, is inherently exploitative, violent or disgusting. The growing recognition of male and transgender sex workers has not led to rethinking or reframing of classic feminist positions around the 'poor helpless prostituted victim'. Continued conflation of 'sex trafficking' with sex work by feminists has further led to the muddying of waters and shrinking of space for sex workers' voices. In many ways the discourse on sex work has been hijacked by the 'sex trafficking' discussion and also by the continued emphasis on sex work as violence, obliterating all other discussions that need to occur to ensure women in sex work a free and safe working environment and agency.

The women's movement has, for several decades now, engaged with issues related to the body. The conflation of sexuality and reproduction, the reduction of women into uteruses and ovaries 
and the fragmentation of women in reproductive health policies demanded an engagement with the construction of the female body and 'control' over it. Where contraception and fertility control mark the convergence of female sexuality and reproduction, sex work marks the convergence of female sexuality and work. This is a convergence that has demanded a complex response.

Morality, double standards, a discomfort with the erotic, accompanied by an unwillingness to listen to sex workers themselves has hindered alliances between what would have been 'natural' allies. Feminist theory and practice - a powerful liberatory force challenging inequities in every sphere - seems to have faltered, and even failed, when it comes to the issue of commercial sex. Often, the feminist movement faltered when it sought to speak on behalf of marginalised women, rather than listen to their voices when they speak. Feminists and sex workers have only recently begun to talk to each other. New learning needs to occur within feminist theory to include the experiences of these women who stand beyond the margins and have a different story to narrate.

\subsection{Violence of stigmatisation}

Stigmatisation, which has its roots in the standards set by patriarchal morality, is experienced as the major factor that prevents women from accessing their rights. The lives of women in sex work are particularly held hostage. Stigmatisation impacts the lives of women in more ways than one. Some of the rights denied due to discrimination are: freedom from physical and mental abuse; the right to education and information; health care; housing; social security and welfare services. The most basic of all is the denial of the right to working in the 'business of making money from sex'.

The sex work narratives are stories of strength that depict women as breadwinners and caretakers of their families and communities. Some of the stories also strongly suggest that any permanent male figure should be avoided. The male stereotype thus developed depicts men as outsiders, visitors and guests, some of whom stay for a long period of time. The ideal way of being is to be independent and in control financially, emotionally and sexually. Motherhood, which is treasured, also excludes any male right to progeny. The woman-centred family thus created tries to gather all women into its bosom and keep men at the fringe. There are also a lot of stories of men who have rejected the patriarchal male stereotype and have tried to break out of its confines. Such men are welcomed and space is made for them within the families of women in sex work.

VAMP claims that this perspective with emotional and financial backing is a potent salve for newcomers into the business who have been abused by mainstream patriarchal society. It is the randi [whore] stigma that pushes women in sex work outside the rights framework, effectively cutting them off from privileges and rights supposedly accorded to all citizens irrespective of what they do for a living. Women in prostitution and sex work from VAMP state that, 'As people who experience violence as a part of our daily lives, we are being more and more penalised by increasing violence in a society that is trying to order and control our lifestyles. As women in prostitution we protest against a society that forces on us the violence of a judgmental attitude' (Sangram 1995).

\subsection{Undressing patriarchy}

The women from VAMP state, 'We as adult women consent to exchange sexual services for money, but this is disputed and our ability to consent is contested. We consider sex work as work, as a business, and do not consider ourselves as either criminals or victims. Because feminism posits prostitution as violence, this viewpoint forecloses any discussion over whether we can actively choose sex work as a livelihood option. It is assumed that we have been coerced into sex work. In order for the stigma of discrimination to end, and fundamental rights extended to us to carry out our livelihood, societal perception must be transformed. We in the business recognise the ills of trafficking and want to fight it. This is only possible if we are strengthened as workers with a right to fight against criminalisation of our trade.'

Sex work where VAMP is located is womencentred and is run for the benefit of the women. Since the discourse regarding sex work is embroiled in the commodification of the female form, the so-called trivialisation of female sexuality, the sacred space of sex and the moral positions put forth by family and like institutions, the discourse put forth by communities of women in sex work is being totally negated. 
Many women in sex work express the view that the freedom they have from both male and societal diktats can find little or no parallel in the lifestyle offered by male-centred systems outside of dhanda. ${ }^{3}$ However, the challenge to patriarchy is not painless. It is precisely because sex work constantly challenges patriarchy, stereotypes and the normative understanding of feminine sexuality that it evokes a sense of unease and agitation amongst those seeking to bear the torch of patriarchy. These attempts at self-expression are often seen as individual defiance and more often result in a woman's humiliation. The struggle for challenging patriarchy has been taken up by a very

\section{Notes}

1 Reclaiming terminology used in Sanskrit for the prostitute [veshya], VAMP was registered in 1997.

2 VMM was represented by Sushila Kunde, Sunita More, Sushma Waghmore, Yeshoda Nyayanith, Shashikala Surve and Sunita

\section{References}

Barry, K. (1979) Female Sexual Slavery, New York: New York University Press

Farley, M. (2004a) "'Bad for the Body, Bad for the Heart": Prostitution Harms Women even if Legalized or Decriminalized', Violence Against Women: 1087-125

Farley, M. (2004b) Prostitution, Trafficking and Traumatic Stress, Binghamton NY: Haworth Maltreatment and Trauma Press

Jenkins, S. (2009) Beyond Gender: An Examination of Exploitation in Sex Work, Keele: Keele University unassuming group of women and needs to be given space in mainstream discourses on patriarchy.

In conclusion, moral and ideological frameworks have successfully managed to marginalise and ignore the contribution women in sex work have made to understand the lives of women who live outside accepted societal norms. From outrage over the exploitation of women's bodies to pity for the hapless victims of male lust, from force to choice, from violence to exploitation, the debates rage while sex workers go about the daily business of earning a livelihood by providing sexual services for money.

Kamble. VAMP was represented by

Meenakshi Kamble, Kamalabai Pani, Shabana Goundi, Durga Pujari, Bhimmawa Gollar and Suvarna Ingalgave.

3 Dhanda is the term used by sex workers within India, Pakistan, Nepal and Bangladesh to describe the sex work industry.

Murthy, Laxmi and Seshu, Meena (forthcoming), Business of Sex, New Delhi: Zubaan Books

Nandita Kapadia Kundu (2011) Engaging Communities in India to Demand their Rights, www.aidstar-one.com/focus_areas/gender/ resources/case_study_series/sangrams collectives (accessed 10 October 2013)

Sangram (1995) A Statement of Women in Prostitution, 28 January, www.sangram.org/resources/sangram-VAMPstatement-1995.pdf (accessed 28 August 2013) Stam, H.L. (1994) Power/Gender, Social Relations in Theory and Practice, London: Sage Publications 